\title{
Structure and Nature of the Metal-Support Interface: Characterization of Iridium Clusters on Magnesium Oxide by Extended X-ray Absorption Fine Structure Spectroscopy
}

\author{
F. B. M. Van Zon, ${ }^{\dagger, \ddagger}$ S. D. Maloney, ${ }^{8}$ B. C. Gates, ${ }^{8, \|}$ and D. C. Koningsberger ${ }^{*}+$ \\ Contribution from the Debye Institute, Laboratory of Inorganic Chemistry and Catalysis, \\ University of Utrecht, P.O. Box 80083, 3508 TB Utrecht. The Netherlands, and Center for \\ Catalytic Science and Technology, Department of Chemical Engineering, University of Delaware, \\ Newark, Delaware 19716
}

Received September 30, 1992. Revised Manuscript Received April 2, $1993^{\circ}$

\begin{abstract}
X-ray absorption spectroscopy was used to characterize the metal-support interface in catalysts consisting of very small Ir clusters of nearly uniform nuclearity on the surface of $\mathrm{MgO}$ powder. [ $\operatorname{Ir}_{4}(\mathrm{CO})_{12}$ ] on $\mathrm{MgO}$ was converted in high yield into $\left[\mathrm{HIr}_{4}(\mathrm{CO})_{11}\right]^{-}$and separately into $\left[\mathrm{Ir}_{6}(\mathrm{CO})_{15}\right]^{2-}$. Extended X-ray absorption fine structure (EXAFS) data are consistent with the hypothesis that each cluster retained its nuclearity upon decarbonylation. The average $\mathrm{Ir}-\mathrm{Ir}$ coordination in $\mathrm{Ir}_{4} / \mathrm{MgO}$ is 2.6 neighbors at a distance of $2.72 \AA$, and the structure is modeled as a mixture of $40-50 \%$ tetrahedra and the remainder four-atom rafts on $\mathrm{MgO}$. The average $\mathrm{Ir}-\mathrm{Ir}$ coordination in $\mathrm{Ir}_{6} / \mathrm{MgO}$ is 2.7 neighbors at a distance of $2.72 \AA$, and the structure is modeled as a mixture of about $25 \% \mathrm{Ir}_{6}$ octahedra and the remainder Ir rafts on $\mathrm{MgO}$. Another sample was treated in $\mathrm{H}_{2}$ at $623 \mathrm{~K}$ to give a typical supported metal catalyst having a distribution of $\mathrm{Ir}$ clusters averaging $10 \AA$ in diameter. The $\mathrm{Ir}$-support interfaces in $\mathrm{Ir}_{4} / \mathrm{MgO}$ and $\mathrm{Ir}_{6} / \mathrm{MgO}$ are characterized by single $\mathrm{Ir}-\mathrm{Mg}$ coordinations at $1.6 \AA$ and fourfold $\mathrm{Ir}-\mathrm{O}$ coordinations at $2.6 \AA$; the interface Ir atoms are suggested to be atop $\mathrm{Mg}$ ions in the $(100)$ faces of $\mathrm{MgO}$. However, this structural model is simplified, and the $\mathrm{Ir}-\mathrm{Mg}$ interactions are not fully understood. The results demonstrate that the structurally simple supported Ir clusters are among the simplest supported metals; the metal-oxygen distances of approximately $2.6 \AA$ are quite generally characteristic of metal particles and clusters supported on metal oxides and zeolites; the long distance is attributed to metal atoms interacting with oxygen of the support with hydrogen present at the interface.
\end{abstract}

\section{Introduction}

Most industrial metal catalysts are dispersed as small particles on high-area metal oxide supports to allow access of reactants to most of the metal atoms. The dispersion is stabilized by metalsupport interactions that hinder particle migration and coalescence that lead to loss of catalytic activity by loss of metal surface area. Metal-support interactions also affect the activities of catalysts, but little is understood about how. ${ }^{1,2}$ The understanding is limited by the lack of precise methods for structural characterization of microscopic metal particles and metal-support interfaces.

The extended X-ray absorption fine structure (EXAFS) technique has provided the first quantitative characterizations of metal-support interface structures in highly dispersed supported metal catalysts. Thorough data have been obtained for $\mathrm{Rh}$ supported on $\gamma-\mathrm{Al}_{2} \mathrm{O}_{3}$ and on $\mathrm{TiO}_{2}{ }^{3-6}$ The EXAFS results for a number of metals on metal oxide supports show metal-oxygen interactions characterized by both short $(1.95-2.05 \AA)^{7-10}$ and

\footnotetext{
* To whom correspondence should be addressed.

t University of Utrecht.

'Part of this work was carried out as a Ph.D. Thesis of the Eindhoven University of Technology, The Netherlands.

University of Delaware.

I Present address: Department of Chemical Engineering, University of California, Davis, CA 95616.

- Abstract published in Advance ACS Abstracts, October 1, 1993.

(1) Stevenson, S. A., Dumestic, J. A., Ruckenstein, E., Eds. Metal-Support Interactions in Catalysis, Sintering and Redispersion; Van Nostrand Reinhold: New York, 1987.

(2) Haller, G. L.; Resasco, D. E. Adv. Catal. 1989, 36, 173.

(3) Van Zon, J. B. A. D.; Koningsberger, D. C.; Van 't Blik, H. F. J,; Sayers, D. E. J. Chem. Phys, 1985, 82, 5742.

(4) Koningsberger, D. C.; Van Zon, J. B. A. D.; Van 't Blik, H. F. J.; Visser, G. J.; Prins, R.; Mansour, A. N.; Sayers, D. E.; Short, D. R.; Katzer, J. R. J. Phys. Chem. 1985, 89, 4075.

(5) Koningsberger, D. C.; Martens, J. H. A.; Prins, R.; Short, D. R.; Sayers, D. E. J. Phys. Chem. 1986, 90, 3047.

(6) Martens, J. H. A.; Prins, R.; Zandbergen, H.; Koningsberger, D. C. J. Phys. Chem. 1988, 92, 1903.
}

long (2.5-2.8 $\AA$ ) distances. ${ }^{3-6}$ The structural implications of these distances are still debated.

The objective of the research described here was to gain fundamental understanding of the chemistry of metal-metal oxide interfaces by investigating structurally simple and well-defined supported metal catalysts. The strategy was to use an organometallic cluster as a precursor to prepare extremely small supported metal clusters with nearly uniform nuclearities (numbers of metal atoms). Small, uniform supported metal clusters offer an excellent opportunity for precise characterization of the metal structure by EXAFS spectroscopy; the smaller the metal cluster, the larger the fraction of the EXAFS signal that arises from the metal-support interface and the greater the opportunity for accurate characterization of the interface structure.

$\left[\operatorname{Ir}_{4}(\mathrm{CO})_{12}\right]$ was chosen to be the precursor, and partially hydroxylated $\mathrm{MgO}$ was chosen to be the support, as the chemistry of Ir carbonyls on the basic $\mathrm{MgO}$ surface is relatively well understood, 11 being similar to that occurring in basic solutions and allowing synthesis in high yields of $\left[\mathrm{HIr}_{4}(\mathrm{CO})_{11}\right]^{-}$and $\left[\mathrm{Ir}_{6}(\mathrm{CO})_{15}\right]^{2-}$ on the surface. ${ }^{12}$ The goal was to form and decarbonylate these cluster anions on the support without changing their nuclearities.

The MgO support offers several advantages for characterization of the samples by X-ray absorption spectroscopy. In contrast to the structurally more complex $\gamma-\mathrm{Al}_{2} \mathrm{O}_{3}$ and $\mathrm{TiO}_{2}, \mathrm{MgO}$ (which

(7) Emrich, R. J.; Mansour, A. N.; Sayers, D. E.; McMillan, S. T.; Katzer, J. R. J. Phys. Chem. 1985, 89, 4261 .

(8) Lytle, F. W.; Greegor, R. B.; Marques, E. C.; Via, G. H.; Sinfelt, J. H. J. Catal. 1985, 95, 546 .

(9) Via, G. H.; Sinfelt, J. H.; Lytle, F. W. J. Chem. Phys. 1979, 71, 690.

(10) Lagarde, P.; Murata, T.; Vlaic, G.; Freund, E.; Dexpert, H.; Bournonville, J. P. J. Catal. 1983, 84, 33.

(11) Maloney, S. D.; Van Zon, F. B. M.; Kelley, M. J.; Koningsberger, D. C.; Gates, B. C. Catal. Lett. 1990, S, 161.

(12) Maloney, S. D.; Kelley, M. J.; Koningsberger, D. C.; Gates, B. C. J. Phys. Chem. 1991, 95, 9406. 

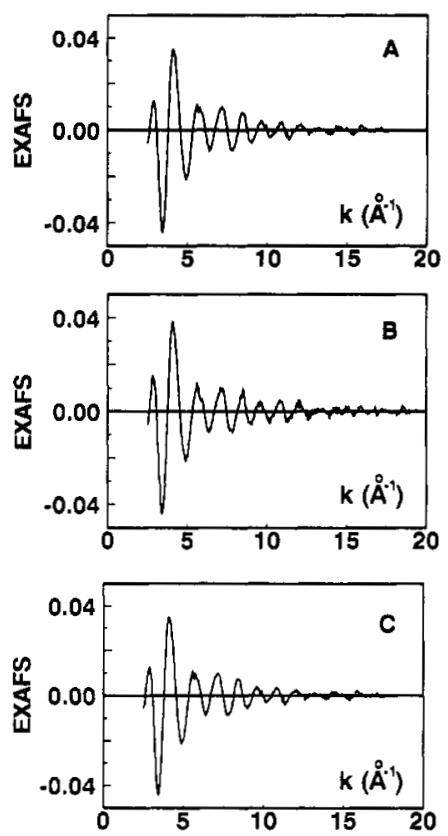

Figure 1. Raw EXAFS data characterizing (A) $\mathrm{Ir}_{4} / \mathrm{MgO}$, (B) $\mathrm{Ir}_{6} / \mathrm{MgO}$, and $(\mathrm{C}) \mathrm{Ir}_{n} / \mathrm{MgO}$.

has the rock salt structure) exhibits predominantly (100) faces, even in the powder form. ${ }^{13}$ Thus the surface of $\mathrm{MgO}$ is relatively simple and well defined and a good choice for characterization of the metal-support interface. Furthermore, as both the $\mathrm{O}^{2-}$ and $\mathrm{Mg}^{2+}$ ions are present in the same surface layers, both the $\mathrm{Ir}-\mathrm{O}$ and $\mathrm{Ir}-\mathrm{Mg}$ interactions are expected to be characterized by the EXAFS data. EXAFS evidence of interactions between supported metals and cations of the support has been reported only rarely. ${ }^{6}$

The results summarized below provide a precise characterization of the metal-support interface. The EXAFS data reduction has been carried out with an improved method, including statistical analysis; the structural parameters are reported with confidence limits determined on the basis of estimates of the noise in the data.

\section{Results}

Supported metals prepared from $\left[\mathrm{Ir}_{4}(\mathrm{CO})_{12}\right]$ and $\mathrm{MgO}$ have been prepared in three different ways. The sample designated $\mathrm{Ir}_{4} / \mathrm{MgO}$ represents that prepared by decarbonylation of $\left[\mathrm{HIr}_{4}(\mathrm{CO})_{11}\right]^{-}$supported on $\mathrm{MgO}$. The sample designated $\mathrm{Ir}_{6}$ / $\mathrm{MgO}$ represents that prepared by conversion of the tetrairidium carbonyl to $\left[\mathrm{Ir}_{6}(\mathrm{CO})_{15}\right]^{2-}$ on $\mathrm{MgO}$, which was then decarbonylated. Another sample, designated $\mathrm{Ir}_{n} / \mathrm{MgO}$, was treated in hydrogen under more forcing conditions to give larger Ir clusters with a distribution of cluster sizes; it is thus representative of a typical highly dispersed supported metal catalyst of the kind used in industry.

The raw EXAFS data characterizing the three samples are shown in Figure 1A, B, and C. The data quality is high; details are given below in the section entitled EXAFS Data Analysis. A demonstration of the data quality is provided by a Fourier transform (Figure 2), calculated with a $k^{3}$ weighting ( $k$ is the wave vector) and application of a correction for the Ir-Ir phase and backscattering amplitude; data were used from $k=2.6$ up to $k=13.5 \AA^{-1}$. For comparison, the Fourier transform of EXAFS data obtained with Ir metal powder (measured at room temperature, thus with more broadened peaks) is also shown.

A preliminary indication of the Ir cluster sizes in the several samples is given by the Fourier transforms of Figure 2. The amplitude of the first-shell Ir-Ir contribution at $2.7 \AA$ (Figure

(13) Henrich, V. C. Rep. Prog. Phys. 1985, 48, 1481.

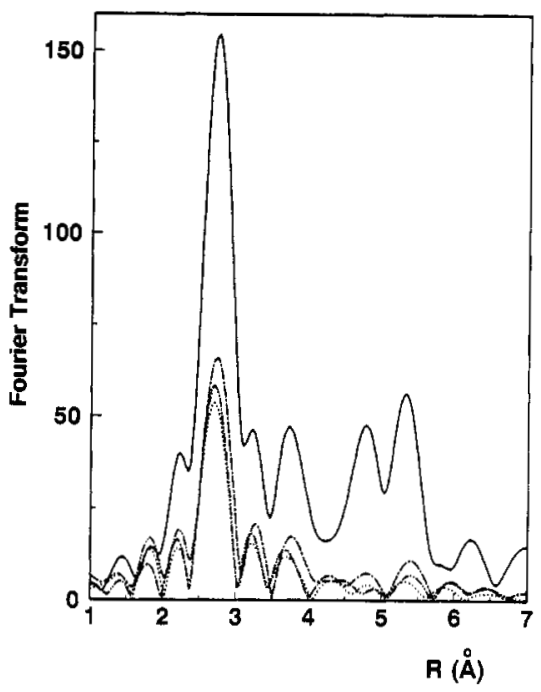

Figure 2. Magnitude of the Fourier transform ( $k^{3}$-weighted, $\Delta k=2.6$ $13.5 \AA^{-1}$ ) of Ir powder (solid line), $\mathrm{Ir}_{n} / \mathrm{MgO}$ (dot-dashed line), $\mathrm{Ir}_{6} / \mathrm{MgO}$ (dot-dot-dashed line), and $\mathrm{I}_{4} / \mathrm{MgO}$ (dotted line).

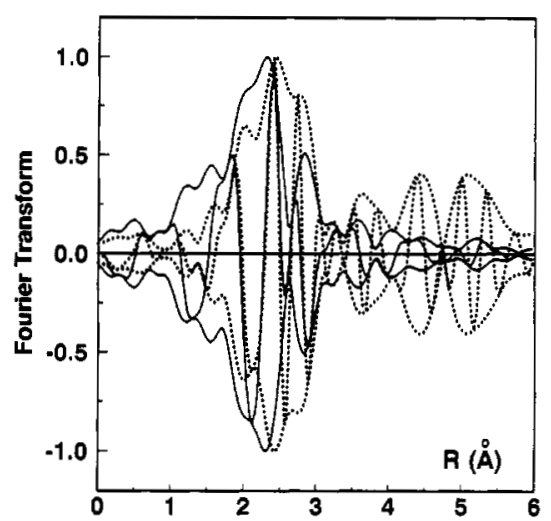

Figure 3. Magnitude (envelope) and imaginary part (oscillations within envelope) of Fourier transform ( $k^{1}$-weighted, $\Delta k=2.6-13.5 \AA^{-1}$ ) of EXAFS function characterizing $\mathrm{I}_{4} / \mathrm{MgO}$ (solid line) and Ir powder (dotted line). Data are scaled to facilitate the comparison.

2) is lower for $\mathrm{Ir}_{4} / \mathrm{MgO}$ than for the other samples, pointing to $\mathrm{Ir}_{4} / \mathrm{MgO}$ as the sample with the highest Ir dispersion. The absence of the third and fourth Ir-Ir shells and the very low amplitude of the second shell (at $3.8 \AA$ ) also point to the high dispersion of the $\mathrm{Ir}_{4} / \mathrm{MgO}$ and $\mathrm{Ir}_{6} / \mathrm{MgO}$. In contrast, the higher $\mathrm{Ir}-\mathrm{Ir}$ coordination shells are clearly evident in the data representing the sample that had been treated in hydrogen at a relatively high temperature $\left(\mathrm{Ir}_{n} / \mathrm{MgO}\right)$, showing the lower dispersion of the Ir. However, even in this sample the Ir clusters were still quite small, as indicated by a comparison of the Fourier transforms of EXAFS data characterizing $\mathrm{Ir}_{n} / \mathrm{MgO}$ and $\mathrm{Ir}$ powder; the second, third, and fourth Ir-Ir shells are much more prominent in the Ir powder data than in the others.

The Fourier transforms presented in Figure 2 are $k^{3}$ weighted and are therefore not appropriate for demonstrating the presence of the low- $Z$ neighbors of $\mathrm{Ir}$ in the support ( $\mathrm{O}$ and $\mathrm{Mg}$ ). The backscattering amplitude of a low- $Z$ element becomes very small at $k \geq 7 \AA^{-1}$, whereas that of a high- $Z$ scatterer is still significant at higher values of $k^{14}$ Application of only $k^{3}$ weighting leads to an underestimation of the contributions of low- $Z$ scatterers, and application of only $k^{1}$ weighting leads to an underestimation of the contributions of high- $Z$ scatterers. Therefore, both weightings were applied. The presence of low- $Z$ neighbors of Ir is demonstrated in Figure 3, which is a comparison of a $k^{1}$-weighted

(14) Koningsberger, D. C.; Prins, R. $X$-Ray Absorption: Principles, Applications, Techniques of EXAFS, SEXAFS and XANES; Wiley: New York, 1988 

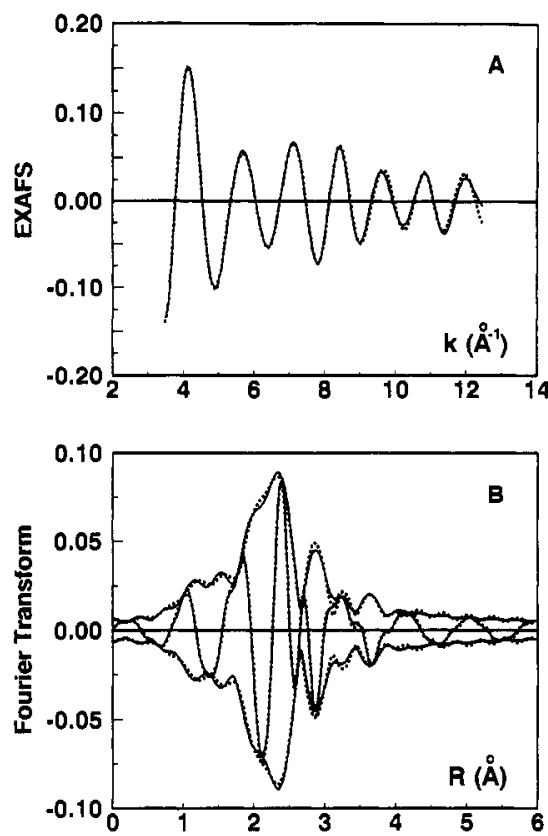

Figure 4. Results of multiple-shell fitting (dotted line) of the EXAFS data characterizing $\operatorname{Ir}_{4} / \mathrm{MgO}$ (solid line): (A) fit in $k$ space ( $k^{1}$-weighted, $\Delta k=3.5-12.5 \AA^{-1}$ ) and (B) fit in $r$ space (FT: $k^{1}$-weighted, $\Delta k=3.5-$ $\left.12.5 \AA^{-1}\right)$.

Fourier transform of data characterizing Ir powder and data characterizing the $\mathrm{Ir}_{4} / \mathrm{MgO}$ sample (the one with the highest dispersion and the most easily detectable support neighbors). Figure 3 shows both the magnitude (the envelope) and the imaginary part (the oscillations) of the $k^{1}$-weighted Fourier transform. The Fourier transform of the EXAFS data characterizing the Ir powder in this figure is scaled to the main peak of the Fourier transform of the EXAFS data characterizing $\mathrm{Ir}_{4} /$ $\mathrm{MgO}$. The peak at the position of the first Ir-Ir shell in Ir powder seems to be split into three peaks; this splitting is caused by the $k$ dependence of the phase shift and backscattering amplitude of the Ir-Ir absorber-backscatterer pair. Application of a Fourier transform that is corrected for the $k$ dependence of the Ir-Ir phase shift and backscattering amplitude shows only one peak for the Ir-Ir contribution ${ }^{15}$ (Figure 2). The contrast between the data in the first-shell region for the two samples (Figure 3, both the magnitudes and the imaginary parts of the Fourier transforms) demonstrates the presence of low- $Z$ scatterers in the immediate neighborhood of $\mathrm{Ir}$ in the $\mathrm{Ir}_{4} / \mathrm{MgO}$ sample; these are inferred to be present in the metal-support interface.

The final results of the EXAFS data analysis are presented for all three samples in Figures 4-6. Fits obtained by a nonlinear least squares multiple-shell fitting routine are shown in $k$ space and in $r$ (distance) space with $k^{1}$ weighting. A statistical justification of the structural parameters and details of the analysis are given in the section entitled EXAFS Data Analysis. The coordination parameters and their standard deviations (calculated from the covariance matrix including the statistical errors of the experimental points), obtained from the nonlinear least squares multiple-shell fitting routine, are given in Table I.

The analysis of the EXAFS data for the $\mathrm{Ir}_{4} / \mathrm{MgO}$ sample showed that the second Ir-Ir shell was significant but the third and fourth shells were not detectable. The difference file (obtained by subtracting the sum of the $\operatorname{Ir}-\operatorname{Ir}(1), \operatorname{Ir}-\mathrm{Mg}$, and $\mathrm{Ir}-\mathrm{O}(1)$ contributions from the primary EXAFS data) provides further evidence of the presence of the second Ir-Ir shell (Figure 7, solid line). The dotted line (Figure 7) represents the second Ir-Ir shell calculated with the parameters obtained from the multiple-shell

(15) Van Zon, F. B. M.; Koningsberger, D. C. Proceedings of the $9 t h$ International Congress on Catalysis; Phillips, M. J., Ternan, M., Eds.; Chemical Institute of Canada: Ottawa, Ontario, 1988; Vol. III, p 1386.
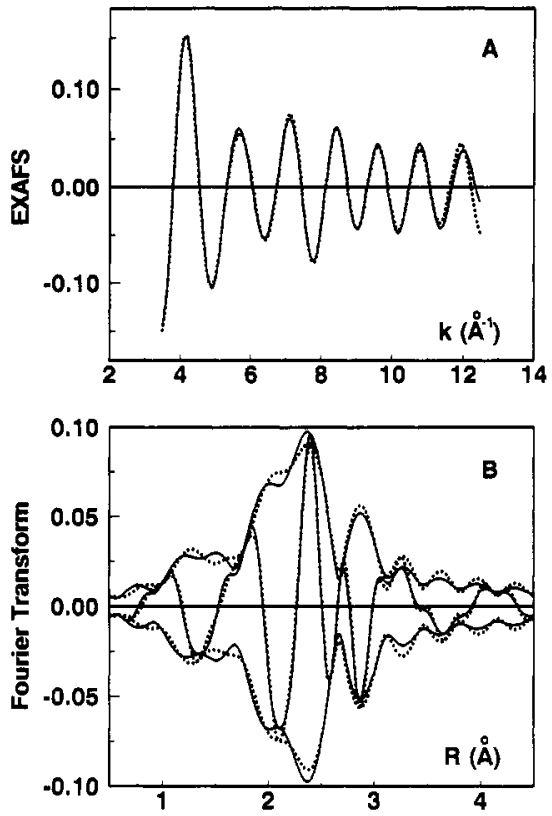

Figure 5. Results of multiple shell fitting (dotted line) of the EXAFS data characterizing $\mathrm{Ir}_{6} / \mathrm{MgO}$ (solid line). (A) fit in $k$ space $\left(k^{1}\right.$-weighted, $\Delta k=3.5-12.5 \AA^{-1}$ ) and (B) fit in $r$ space (FT: $k^{1}$-weighted, $\Delta k=3.5-$ $\left.12.5 \AA^{-1}\right)$.
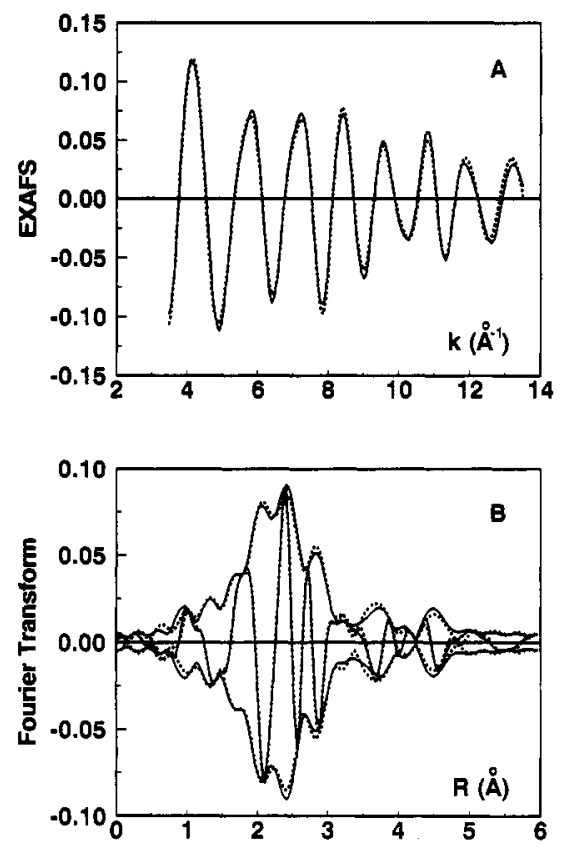

Figure 6. Results of multiple-shell fitting (dotted line) of the EXAFS data characterizing $\mathrm{Ir}_{n} / \mathrm{MgO}$ (solid line): (A) fit in $k$ space ( $k^{1}$-weighted, $\Delta k=3.5-13.5 \AA^{-1}$ ) and (B) fit in $r$ space (FT: $k^{1}$-weighted, $\Delta k=3.5-$ $\left.13.5 \AA^{-1}\right)$.

fit. The coordination parameters characterizing the second shell are included in Table I for comparison with the results of the higher-shell analysis of the data for $\mathrm{Ir}_{n} / \mathrm{MgO}$. The second $\mathrm{Ir}-\mathrm{Ir}$ shell for $\mathrm{Ir}_{6} / \mathrm{MgO}$ was difficult to analyze with the nonlinear least squares fitting routine because other, overlapping highershell contributions are present in the data. These weak contributions prevented a reliable analysis of the second Ir-Ir shell with the fitting routine. The data characterizing $\mathrm{Ir}_{n} / \mathrm{MgO}$ allow analysis of the second and third Ir-Ir shells. Coordination parameters for these shells are included in Table $\mathbf{I}$.

The $\mathrm{Ir}-\mathrm{O}(1)$ and $\mathrm{Ir}-\mathrm{Mg}$ contributions are evidence of the metal-support interactions. These contributions are shown for the $\mathrm{Ir}_{4} / \mathrm{MgO}$ sample in Figure 8A and $\mathrm{B}$. The $\mathrm{Ir}-\mathrm{O}(1)$ EXAFS function was determined by subtraction of the calculated sum of 
Table I. Coordination Parameters

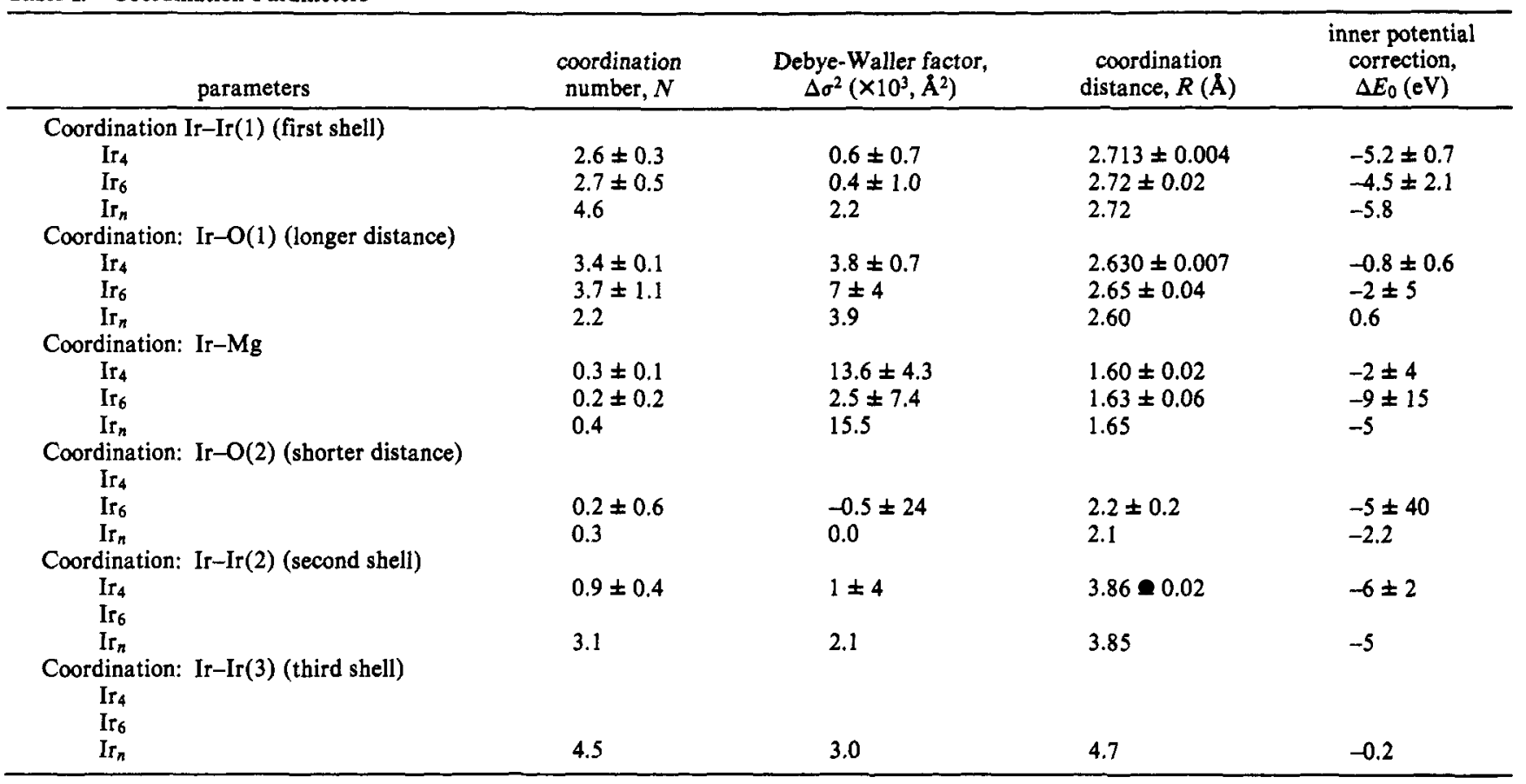

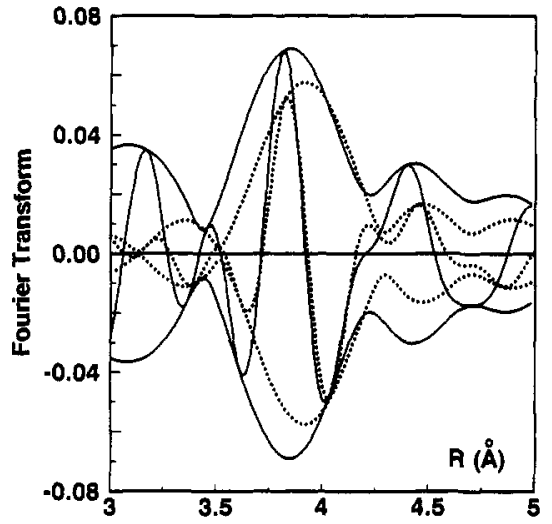

Figure 7. Fourier transform ( $k^{3}$-weighted, $\Delta k=3.5-12.5 \AA^{-1}$, Ir-Ir phase- and amplitude-corrected) of the difference file (isolated EXAFS minus calculated $\operatorname{Ir}-\operatorname{Ir}(1)+\mathrm{Ir}-\mathrm{O}(1)+\mathrm{Ir}-\mathrm{Mg}$ ) (solid line) and calculated $\operatorname{Ir}-\operatorname{Ir}(2)$ EXAFS function (dotted line) for $\mathrm{Ir}_{4} / \mathrm{MgO}$ (notation in Table I).

the $(\operatorname{Ir}-\operatorname{Ir}(1))+(\operatorname{Ir}-\mathrm{Mg})$ contributions from the primary EXAFS data by using the coordination parameters obtained from the best fit. Similarly, the Ir-Mg EXAFS function was obtained by subtraction of the calculated $(\operatorname{Ir}-\operatorname{Ir}(1))+(\operatorname{Ir}-\mathrm{O}(1))$ contribution from the primary data. The Ir-O phase-corrected Fourier transform peaks at about $2.6 \AA$, and the Ir-Mg phase-corrected Fourier transform peaks at about $1.6 \AA$. A summary plot showing the different contributions ( $\operatorname{Ir}-\operatorname{Ir}(1)$ and $\mathrm{Ir}-\mathrm{O}(1)$ ) for $\mathrm{Ir}_{4} / \mathrm{MgO}$ and $\mathrm{Ir}_{n} / \mathrm{MgO}$ is shown in Figure 9. The results show that with increasing cluster size there is an increasing $\operatorname{Ir}-\operatorname{Ir}(1)$ contribution and a decreasing $\mathrm{Ir}-\mathrm{O}(1)$ contribution; this is the expected pattern, as the metal-support interface is represented by the $\mathrm{I} r-\mathrm{O}$ (1) contribution.

The X-ray absorption near edge structure (XANES) provides further evidence of the structures of the supported metal clusters. The normalized $\mathrm{L}_{\text {III }}$ absorption edge (white line) data for two supported $\mathrm{Ir}$ samples $\left(\mathrm{Ir}_{4} / \mathrm{MgO}\right.$ and $\left.\mathrm{Ir}_{n} / \mathrm{MgO}\right)$ and for $\mathrm{Ir}$ metal powder are summarized in Figure 10A. The decreasing intensity of the white line with increasing cluster size is consistent with predictions of Hartree-Fock-Slater LCAO calculations characterizing $\mathrm{Ir}_{4}$ and $\mathrm{Ir}_{10}$ clusters. ${ }^{16}$ However, the intensity of the $\mathrm{L}_{\mathrm{III}}$ absorption edge characteristic of $\mathrm{Ir}_{6} / \mathrm{MgO}$ is slightly higher
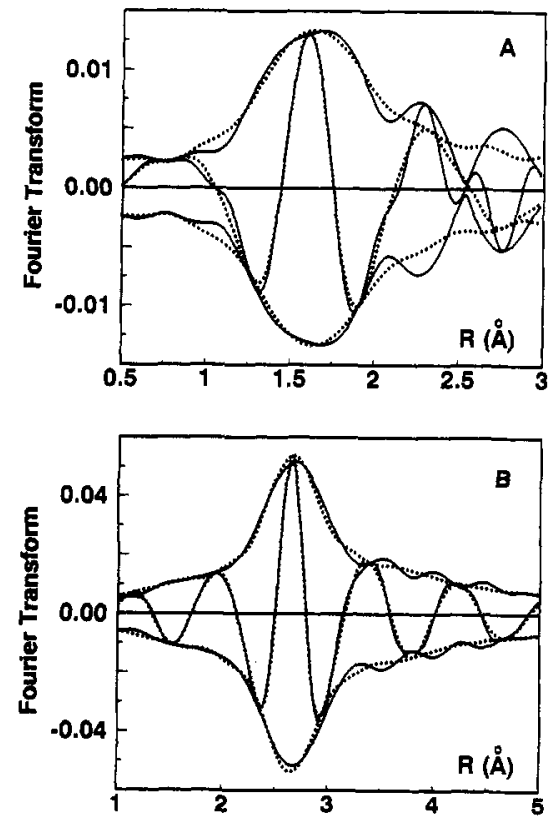

Figure 8. (A) Fourier transform ( $k^{3}$-weighted, $\Delta k=3.5-12.5 \AA^{-1}$, Ir$\mathrm{Mg}$ phase-corrected) of difference file (isolated EXAFS minus calculated $\operatorname{Ir}-\operatorname{Ir}(1)+\operatorname{Ir}-\mathrm{O}(1))$ (solid line) and calculated Ir-Mg EXAFS function (dotted line) for $\mathrm{Ir}_{4} / \mathrm{MgO}$. (B) Fourier transform ( $k^{3}$-weighted, $\Delta k=$ 3.5-12.5 $\AA^{-1}$, Ir-O phase-corrected) of difference file (isolated EXAFS minus calculated Ir-Ir (1) + Ir-Mg) (solid line) and calculated Ir-O(1) EXAFS function (dotted line) for $\mathrm{Ir}_{4} / \mathrm{MgO}$.

than that of $\mathrm{Ir}_{4} / \mathrm{MgO}$ (Figure 10B), indicating an effect separate from that of the cluster nuclearity.

\section{Discussion}

Advantage of Organometallic Precursors. A unique advantage of the organometallic precursors is the opportunity they of fer for preparation of extremely small supported metal clusters that are almost optimally suited to precise characterization with EXAFS spectroscopy. The results of this work give evidence that the tetrairidium cluster can be decarbonylated on the support with

(16) Ravenek, W.; Jansen, A. P. J.; Van Santen, R. A. J. Phys. Chem. $1989,93,6445$. 


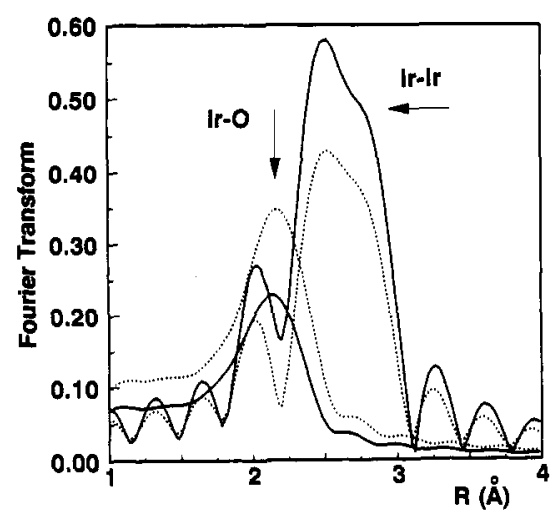

Figure 9. Magnitude of Fourier transform ( $k^{2}$-weighted, $\Delta k=3.5-12.5$ $\AA^{-1}$ ) of calculated $\operatorname{Ir}-\operatorname{Ir}(1)$ and $\operatorname{Ir}-O(1)$ EXAFS functions characterizing $\mathrm{Ir}_{n} / \mathrm{MgO}$ (solid line) and $\mathrm{Ir}_{4} / \mathrm{MgO}$ (dotted line).
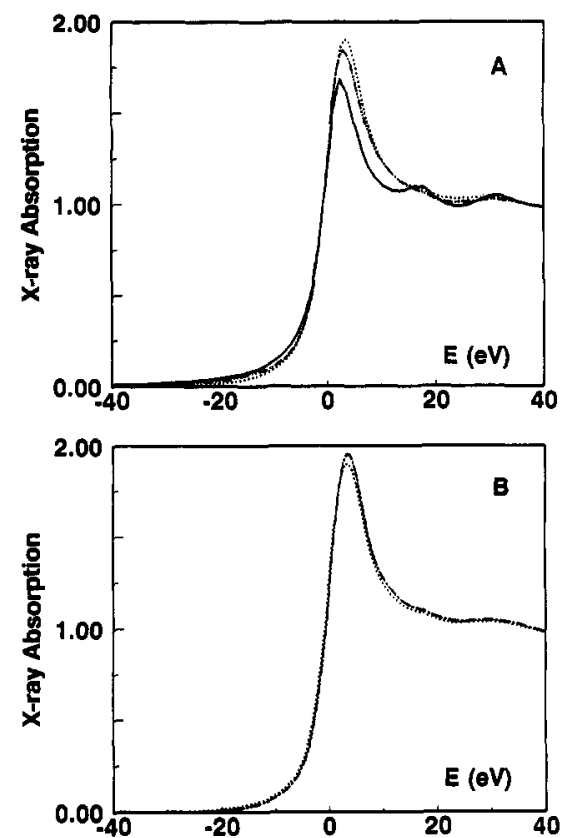

Figure 10. Normalized $L_{\text {III }} X$-ray absorption edge of (A) Ir powder (solid line), $\mathrm{I}_{n} / \mathrm{MgO}$ (dot-dashed line), and $\mathrm{Ir}_{4} / \mathrm{MgO}$ (dotted line) and (B) $\mathrm{Ir}_{4} / \mathrm{MgO}$ (dotted line) and $\mathrm{Ir}_{6} / \mathrm{MgO}$ (dot-dashed line).

little change in nuclearity (Table I). Since the clusters are so small, the EXAFS signal is determined in large measure by the metal-support interactions and not just the metal-metal interactions. Consequently, the EXAFS data offer the prospect of detailed characterization of the structure of the metal-support interface. The samples that usually yield the most explicit structural information from EXAFS analysis are those that are most nearly uniform in structure. Thus an important result of the EXAFS analysis for $\mathrm{Ir}_{4} / \mathrm{MgO}$ is the evidence that the structure is indeed relatively simple and uniform.

Variations in Cluster Size. The chemistry of the Ir carbonyls on $\mathrm{MgO}$ is relatively well defined, being analogous to that occurring in basic solutions. ${ }^{11,12}$ Control of this chemistry allows conversion of the tetrairidium carbonyl precursor in high yield into a hexairidium carbonyl precursor, $\left[\mathrm{Ir}_{6}(\mathrm{CO})_{15}\right]^{2-} .12$ Treatment in He followed by $\mathrm{H}_{2}$ leading to decarbonylation of this cluster gave a supported metal with nearly as high a dispersion as that for the supported metal formed by decarbonylation of the $\mathrm{Ir}_{4}$ cluster on $\mathrm{MgO}$. The high dispersions of these two samples are shown by the extremely small $\operatorname{Ir}-\operatorname{Ir}(1)$ coordination numbers (Table I). The $\operatorname{Ir}-\operatorname{Ir}(1)$ coordination number for $\mathrm{Ir}_{n} / \mathrm{MgO}$ is significantly larger (Table I).

This comparison of coordination numbers is important because it shows that the samples provide a systematic variation of the
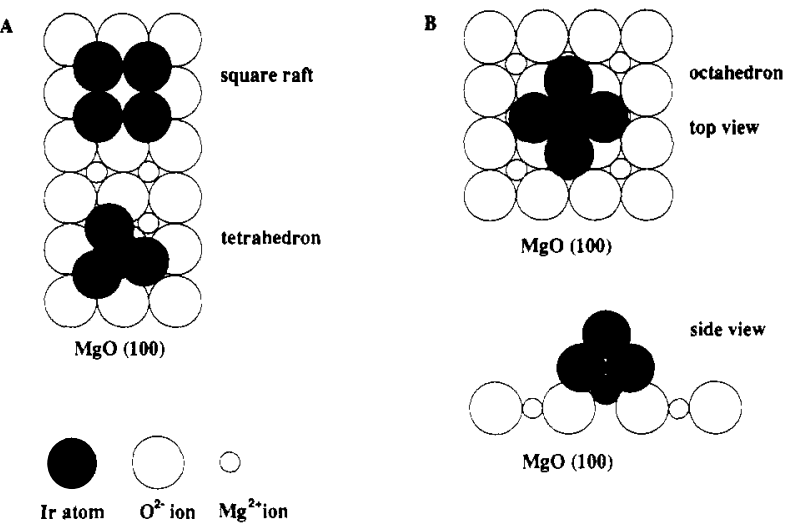

Figure 11. (A) Structural model of $\mathrm{Ir}_{4} / \mathrm{MgO}$ based on EXAFS data. The $\mathrm{MgO}$ (100) surface is assumed. (B) Structural model of the octahedral cluster in $\mathrm{Ir}_{6} / \mathrm{MgO}$ based on EXAFS data.

cluster size and therefore the opportunity for discerning a pattern of changes in the metal-support interface as the fraction of the metal atoms that are in the interface decreases. The data thus offer a unique opportunity to make connections between the relatively precise structural information characteristic of the $\mathbf{I r}_{4}$ and $\mathrm{Ir}_{6}$ clusters and that representative of the structurally less uniform $\mathrm{Ir}_{n} / \mathrm{MgO}$ sample, which is more nearly representative of a typical highly dispersed supported metal catalyst.

Structures of the Supported Iridium Clusters. The results of Table I demonstrate that the metal clusters in the $\mathrm{Ir}_{4} / \mathrm{MgO}$ and $\mathrm{Ir}_{6} / \mathrm{MgO}$ samples are so small that it is possible to give an accurate characterization of the metal-support interface. The data allow a more detailed structural characterization of supported metals-including the metal-support interface-than any yet reported.

From the EXAFS results in Table I it is concluded that the three samples, representing a range of cluster sizes (as demonstrated by the $\operatorname{Ir}-\operatorname{Ir}(1)$ coordination numbers, Table I), are much alike insofar as coordination distances are concerned. However, significant differences are observed in the Debye-Waller factors of the interface contributions, and these indicate that with changes in cluster size there are significant changes in the structural detail of the $\mathrm{Ir}-\mathrm{MgO}$ interface.

$\mathbf{I r}_{\mathbf{4}} / \mathbf{M g O}$. The $\operatorname{Ir}-\operatorname{Ir}(1)$ coordination number characteristic of the sample formed by decarbonylation of $\left[\mathrm{HIr}_{4}(\mathrm{CO})_{11}\right]^{-}$on $\mathrm{MgO}$ (Table I), namely 2.6 , is consistent with the inference that the cluster nuclearity was maintained. However, within the experimental error (Table I), this value is less than 3.0 , the value characteristic of the tetrahedron of the metal frame of the precursor $\left[\mathrm{Ir}_{4}(\mathrm{CO})_{12}\right]$ or $\left[\mathrm{HIr}_{4}(\mathrm{CO})_{11}\right]^{-}$, which implies that the tetrahedral frame of the precursor was not retained in all the clusters. It is also evident from the presence of the second-shell Ir-Ir contribution that a simple $\mathrm{Ir}_{4}$ tetrahedron is not consistent with the data (no higher Ir-Ir shells are expected for a tetrahedron). However, the average Ir-Ir coordination number of 2.6 cannot be reconciled with raft-like structures alone either, as the first-shell Ir-Ir coordination number in a square $\mathrm{Ir}_{4}$ raft is 2 and much larger rafts must be assumed to account for $N=$ 2.6 (but these imply sizeable third and fourth Ir-Ir shells). A small fraction of clusters with nuclearities greater than four may have been present; however, as the third and fourth Ir-Ir shells are almost absent, these must have been rare. There is no conclusive evidence that raft-like structures would be exclusively square; various other arrangements cannot be ruled out.

The EXAFS data have been modeled as simply as possible; they have been found to be consistent with a mixture of $\mathrm{Ir}_{4}$ tetrahedra and square rafts (see Figure 11A). Taking the accuracy of the EXAFS coordination numbers into account, we calculate from the first-shell Ir-Ir coordination number $(2.6 \pm$ 0.3 ) that $40-80 \%$ of the clusters consist of tetrahedra. On the 
other hand, following the same procedure and using the second Ir-Ir shell $(N=0.9 \pm 0.4)$, a maximum of $50 \%$ of the clusters are inferred to be tetrahedra. Combining these results leads to the model that $40-50 \%$ of the Ir clusters are tetrahedra and the remainder square rafts.

The metal is depicted as bare atoms on the support, but the samples were investigated in the presence of hydrogen and were therefore likely Ir hydrides, possibly with a $\mathrm{Ir}^{\delta+}-\mathrm{H}^{\delta-}$ charge distribution; ${ }^{17}$ the available data provide no direct evidence of the locations of the hydrogen atoms in the structure.

$\mathbf{I r}_{6} / \mathbf{M g O}$. The coordination number for the first Ir-Ir shell (2.7) and the very small amplitude of the higher Ir-Ir shells in $\mathrm{Ir}_{6} / \mathrm{MgO}$ show that there was little coalescence of the original clusters. On the other hand, it is also clear that the original octahedral cluster frame was not maintained in a large fraction of the supported Ir clusters (the first-shell coordination number of an octahedron is 4). The data of Figure 2 show that a significant second $\mathrm{Ir}-\mathrm{Ir}$ shell was present and, as for $\mathrm{Ir}_{4} / \mathrm{MgO}$, the contribution of the third Ir-Ir shell is negligible. These observations lead to the conclusion that a significant fraction of the Ir atoms in $\mathrm{Ir}_{6} / \mathrm{MgO}$ were in two-dimensional structures.

As for $\mathrm{Ir}_{4} / \mathrm{MgO}$, we have attempted to model the structures as simply as possible to account for the EXAFS data. Good agreement was obtained with a model consisting of a mixture of octahedra (first Ir-Ir shell coordination number $=4$ ) (Figure $11 B$ ) and $2 \times 3(100)$ rafts (first shell Ir-Ir coordination number $=2.3$ ), but we emphasize again that the existence of other raftlike structures cannot be ruled out. On the basis of the overall first-shell Ir-Ir coordination number determined by EXAFS spectroscopy (2.7), it is estimated that about $25 \%$ of the $\mathrm{Ir}_{6}$ clusters were octahedral.

$\mathbf{I r}_{n} / \mathbf{M g O}$. The EXAFS data characterizing the conventional supported metal catalyst symbolized as $\mathrm{Ir}_{n} / \mathbf{M g O}$ (Table I) give an average $\mathrm{Ir}-\mathrm{Ir}$ distance of $2.72 \AA$; this is consistent with the inference that the structure is metallic and reduction is almost complete (no evidence is found for the presence of iridium oxide, which would show in an $\mathrm{Ir}-\mathrm{O}$ contribution with $R$ around 1.95 $\AA$ ). The metal clusters in such a catalyst are usually threedimensional, sometimes approximated as hemispherical. ${ }^{3}$ The higher-shell EXAFS data, represented by the spectrum in $r$ space (Figure 2), confirm that the Ir particles in $\mathrm{Ir}_{n} / \mathrm{MgO}$ are threedimensional; both second and third metal-metal shells are present. ${ }^{18}$

The $\mathrm{Ir}_{n} / \mathrm{MgO}$ sample, in contrast to the others, is characterized by a distribution of metal cluster sizes (and probably shapes), as its preparation was carried out under severe conditions that led to cluster fragmentation and metal aggregation. An average Ir cluster diameter of $10 \AA$ was estimated from the Ir-Ir coordination number determined with EXAFS spectroscopy (the clusters were assumed to be hemispheres with the fccstructure ${ }^{3}$ ). This estimate implies that on average there were approximately 14 Ir atoms per cluster. Thus, even after the severe treatment used to prepare this sample, the metal clusters are still small and comparable to the $\mathrm{Pt}$ clusters present in typical highly dispersed $\mathrm{Pt} / \mathrm{Al}_{2} \mathrm{O}_{3}$ catalysts. ${ }^{19}$

A comparison of the relative magnitudes of the higher Ir-Ir shells in $\mathrm{Ir}_{n} / \mathrm{MgO}$ and Ir powder (Figure 2) might at first seem to suggest that the Ir particles in $\mathrm{Ir}_{n} / \mathrm{MgO}$ are not well approximated as hemispheres. The high amplitude of the second Ir-Ir shell would be consistent with flatter structures. However, calculations for small fcc model clusters having a (100) basal plane showed that a high amplitude of the second metal-metal shell is consistent with approximately hemispherical clusters.

(17) Kip, B. J.; Duivenvoorden, F. B. M.; Koningsberger, D. C.; Prins, R J. Am. Chem. Soc. 1986, 108, 5633

(18) Kampers, F. W. H.; Engelen, C. W. R.; Van Hooff, J. H. C. Koningsberger, D. C. J. Phys. Chem. 1990, 94, 8574.

(19) Koningsberger, D. C.; Sayers, D. E. Solid State Ionics 1985, 16, 23.
XANES. The relative intensities of the $L_{\text {III }}$ white line of samples such as the supported Ir clusters are usually interpreted as a measure of the d-band density of states. Recent Hartree-FockSlater LCAO calculations ${ }^{16}$ carried out for $\mathrm{Ir}_{4}$ and $\mathrm{Ir}_{10}$ clusters showed a decrease in the number of unfilled d-states (i.e., a decrease in the $\mathrm{X}$-ray absorption white line intensity) with increasing cluster size as a consequence of the better screening in the larger clusters of the core hole of the ionized atom. Indeed, for $\mathrm{Ir}_{4} / \mathrm{MgO}, \mathrm{Ir}_{n} / \mathrm{MgO}$, and Ir powder, the observed trend agrees with expectations; the intensity of the $\mathrm{L}_{\text {III }}$ white line decreases from $\mathrm{Ir}_{4}$ to Ir powder, consistent with the increasing size of the Ir clusters. The same trend was observed for a series of $\mathrm{Pt} / \mathrm{SiO}_{2}$ catalysts; the number of unfilled d-states was determined both from the $L_{I I}$ and $L_{I I I}$ edges. ${ }^{20}$ However, on the basis of this reasoning alone, the white line intensity data for $\mathrm{Ir}_{4} / \mathrm{MgO}$ and $\mathrm{Ir}_{6} / \mathrm{MgO}$ would suggest the presence of smaller clusters in $\mathrm{Ir}_{6} /$ $\mathrm{MgO}$ than in $\mathrm{Ir}_{4} / \mathrm{MgO}$, and the EXAFS results show the reverse. The suggested anchoring of some of the $\mathrm{Ir}_{6}$ clusters to the $\mathrm{MgO}$ at vacancies (reflected in the small $\mathrm{Ir}-\mathrm{O}$ contribution at $2.1-2.2$ $\AA$ ) may influence the intensity of the white line.

Geometry in the Metal-Support Interface. The Ir-O and Ir$\mathrm{Mg}$ contributions are pronounced in the EXAFS data, especially for $\mathrm{Ir}_{4} / \mathrm{MgO}$ and $\mathrm{Ir}_{6} / \mathrm{MgO}$. These contributions are attributed to the metal-support interface. Since the EXAFS coordination parameters are averages over all the Ir atoms in the sample, the coordination numbers characteristic of the $\mathrm{Ir}-\mathrm{O}$ interaction determined in a straightforward EXAFS analysis must be corrected to determine the Ir-O coordination number characteristic of the Ir atoms at the metal-support interface, which are only a fraction of the total. Such a correction has been reported for reduced $\mathrm{Rh} / \gamma-\mathrm{Al}_{2} \mathrm{O}_{3}$; calculations were made on the basis of the assumption of hemispherical metal particles. ${ }^{3}$ A corrected $\mathrm{Rh}-\mathrm{O}$ coordination number of approximately 4.5 was determined for $\mathrm{Rh} / \mathrm{MgO}{ }^{21}$

Similarly, it is possible to determine a corrected $\mathrm{Ir}-\mathrm{O}(1)$ coordination number for the $\mathrm{Ir}_{n} / \mathrm{MgO}$ sample. Using the coordination numbers for $\operatorname{Ir}-\operatorname{Ir}(1)$ (4.6) and $\operatorname{Ir}-\mathrm{O}(1)(2.2)$ determined in the EXAFS analysis as input, the actual iridiumoxygen coordination number $N(i)$ for an iridium atom present in the metal-support interface has been found to be 3.5.

The actual interfacial iridium-oxygen coordination number for the $\mathrm{Ir}_{4} / \mathrm{MgO}$ sample can be calculated directly from the coordination number determined for the $\mathrm{Ir}-\mathrm{O}(1)$ shell (3.4) using the earlier estimated fraction of iridium clusters present as a tetrahedron on the $\mathrm{MgO}(100)$ surface (0.5). In the tetrahedron, $75 \%$ and, in the raft, $100 \%$ of the iridium atoms are present in the metal-support interface. This leads to the following equation: $(0.5 \times 0.75 \times N(i))_{\mathrm{tet}}+(0.5 \times 1 \times N(i))_{\mathrm{raft}}=3.4$, resulting in $N(i)=3.9$.

Taking into account the experimental errors in the EXAFS data (Table I), we might therefore suggest that the Ir-MgO interface could be modeled with an $\mathrm{I} r-\mathrm{O}$ coordination number of 4; a fourfold $\mathrm{Ir}-\mathrm{O}$ coordination can be visualized on the (100) face of $\mathrm{MgO}$. This is the predominant face. ${ }^{13}$ However, it is not appropriate to rule out clusters on other fourfold sites, on other faces, and at imperfections on the $\mathrm{MgO}$ surface where the coordination is less; the data are not sufficient to distinguish these possibilities.

In $\mathrm{Ir}_{6} / \mathrm{MgO}$, in addition to the interface contributions characterized by an $\mathrm{Ir}-\mathrm{O}(1)$ distance at $2.65 \AA$ and an $\mathrm{Ir}-\mathrm{Mg}$ distance at $1.63 \AA$, there is an $\operatorname{Ir}-\mathrm{O}(2)$ shell at $2.2 \AA$ that is not found in the EXAFS data for $\mathrm{Ir}_{4} / \mathrm{MgO}$. The identification of this Ir$O(2)$ contribution is not obvious; we suggest that it may be an indication that some of the clusters are positioned at surface

(20) Mansour, A. N.; Cook, J. W.; Sayers, D. E. J. Phys. Chem. 1984, 88, 2230 .

(21) Van Zon, F. B. M. Ph.D. Thesis. Eindhoven University of Technology, The Netherlands, 1988. 
defects such as $\mathrm{Mg}$ cation vacancies. For example, a structure such as that suggested in Figure 11B (with one atom of the octahedron located at a cation vacancy) could account for anchoring of the octahedron to the support. Replacement of the $\mathrm{Mg}$ cation for Ir results in an $\mathrm{Ir}-\mathrm{O}$ coordination distance of 2.11 $\AA$ if that Ir atom takes the exact Mg cation position, close enough to the observed $\mathrm{Ir}-\mathrm{O}(2)$ distance of $2.2 \AA$. A relatively rigid structure such as this would account for the small Debye-Waller factor observed (Table I) for the $\mathrm{Ir}-\mathrm{Mg}$ contribution at $1.63 \AA$ and the $\mathrm{Ir}-\mathrm{O}(2)$ shell at $2.2 \AA$. Such a structure also provides an explanation for the large Debye-Waller factor observed for the $\mathrm{Ir}-\mathrm{O}$ (1) contribution at $2.65 \AA$ : Four of the octahedral Ir atoms are suggested to be positioned on the $\mathrm{MgO}$ surface, but there would be a large variation in the $\mathrm{Ir}-\mathrm{O}$ distances associated with these $\mathrm{Ir}$ atoms because of the lattice mismatch with $\mathrm{MgO}$.

The coordination numbers calculated for the $\mathrm{Ir}-\mathrm{O}$ contributions in this model agree well with those obtained from EXAFS analysis. In the raft, all the Ir atoms contribute to the $\mathrm{Ir}-\mathrm{O}(1)$ shell at 2.65 $\AA$ (with $N(1)_{\text {raft }}=4$ ) and there is no $\mathrm{Ir}-\mathrm{O}(2)$ contribution $\left(N(2)_{\text {raft }}=0\right)$. In the octahedron, only one Ir atom out of the six (the anchoring atom) contributes to the $\mathrm{Ir}-\mathrm{O}(2)$ shell, and this one has four $\mathrm{Ir}-\mathrm{O}(2)$ interactions; the overall octahedral coordination number is $N(2)_{\text {oct }}=4 / 6$. Four of the octahedral Ir atoms contribute to the $\mathrm{Ir}-\mathrm{O}$ (1) shell at $2.65 \AA$ (fourfold bonding); thus the overall octahedral coordination number for this shell is $N(1)_{\text {oct }}=16 / 6$. For a comparison with the EXAFS results for $\mathrm{Ir}_{6} / \mathrm{MgO}$, the coordination numbers calculated above have to be weighted according to the occurrence of the rafts and octahedra: $N($ EXAFS $)=0.75 N_{\text {raft }}+0.25 N_{\text {oct }}$. In this way, $N(\mathrm{Ir}-\mathrm{O}(2))=$ 0.17 is calculated (the corresponding value determined in the EXAFS analysis, $N(\mathrm{Ir}-\mathrm{O}(2))$, is 0.2 , Table I), and similarly, $N(\mathrm{Ir}-\mathrm{O}(1))=3.67$ (vs 3.7 from the EXAFS analysis).

The suggestion that most of the Ir clusters are present on the (100) faces of $\mathrm{MgO}$ is supported by the relative magnitudes of the Ir-Ir shells. The large amplitude of the second shell with respect to the third (Figure 2) points to Ir rafts as a substantial contribution to the metal structures in $\mathrm{Ir}_{4} / \mathrm{MgO}$ and $\mathrm{Ir}_{6} / \mathrm{MgO}$ and indicates the relatively large contribution of the basal plane of the clusters in $\mathrm{Ir}_{n} / \mathrm{MgO}$. Ir rafts with the (100) arrangement might be expected to provide the best (epitaxial) fit on the $\mathrm{MgO}$ (100) plane, as has been assumed in the models mentioned above. The assumption of rafts with this structure on the $\mathrm{MgO}(100)$ plane accounts for the large differences in the Debye-Waller factor $\left(\Delta \sigma^{2}\right)$ observed for the Ir-Mg contributions (Table I). The largest Debye-Waller factor (indicating the largest distribution of $\mathrm{Ir}-\mathrm{O}$ and $\mathrm{Ir}-\mathrm{Mg}$ distances) would be expected for the sample with the largest interfacial area (i.e., the largest clusters) $\left(\mathrm{Ir}_{n} /\right.$ $\mathrm{MgO}$ ), corresponding to the lattice mismatch of $9 \%$ (the $\mathrm{Ir}-\mathrm{Ir}$ distance is $2.72 \AA$ and the $\mathrm{MgO}$ lattice constant is $2.98 \AA^{13}$ ). However, the largest value of $\Delta \sigma^{2}$ was observed for $\mathrm{Ir}_{4} / \mathrm{MgO}$, the sample with the smallest clusters. This result might be taken as an indication that a significant fraction of the $\mathrm{Ir}_{4}$ clusters were present at surface defects. Alternatively, if it is correct to assume that the $\mathrm{Ir}_{4}$ clusters were largely present on the (100) plane, then the value of the Debye-Waller factor can be explained as follows: A large fraction of the $\mathrm{Ir}_{4}$ clusters is calculated to be present as tetrahedra, and these clusters expose a trigonal basal plane, which does not conform to the square (100) face of MgO (Figure 11A).

Nature of the Metal-Support Interface. The EXAFS observations raise fundamental questions about the nature of the interactions at metal-support interfaces. It has been suggested that the long metal-oxygen distances (2.6-2.8 $\AA$ ) observed in this work and for numerous other samples, as stated in the introduction, may indicate the presence of hydrogen in the metalsupport interface ${ }^{22}$ or, alternatively, interactions of metal atoms with hydroxyl groups of the surface. ${ }^{22,23}$

(22) Koningsberger, D. C.; Gates, B. C. Catal. Lett. 1992, 14, 271.

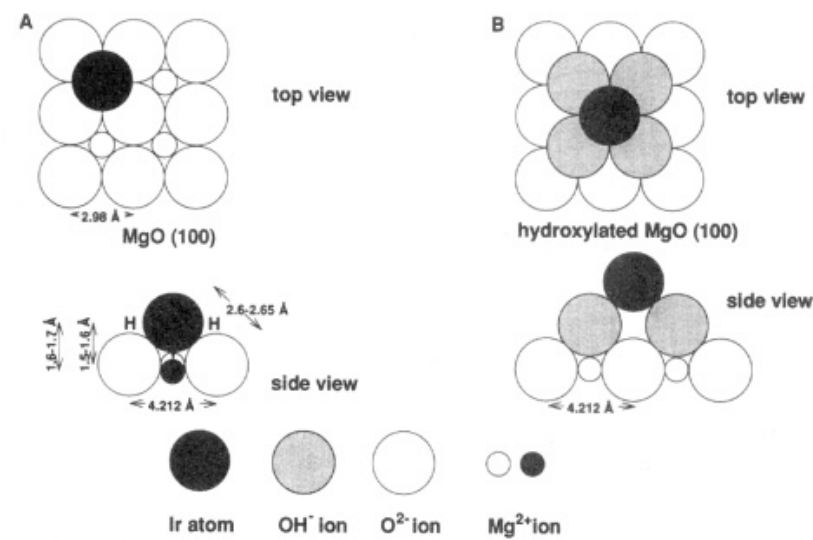

Figure 12. Structural models of the $\mathrm{Ir}-\mathrm{MgO}$ interface. (A) Ir metal atom on a partially hydroxylated $\mathrm{MgO}(100)$ surface with hydrogen in the metal-oxygen interface. (B) Ir metal atom on a fully hydroxylated $\mathrm{MgO}(100)$ surface.

The suggestion that the metal atoms of the clusters were in contact with hydroxyl groups of the support has been tested in experiments with a reduced $\mathrm{Ir} / \gamma-\mathrm{Al}_{2} \mathrm{O}_{3}$ sample evacuated at a high temperature $(623 \mathrm{~K})$; EXAFS results demonstrated that the evacuation led to the disappearance of the long metal-oxygen distance. ${ }^{24}$ Instead, a metal-oxygen distance of about $2.2 \AA$ was detected. The evacuation of the sample is expected to have led to a dehydroxylation of the support, which in turn may have removed $\mathrm{OH}$ groups from the metal-support interface. This shorter metal-oxygen distance might be interpreted as evidence that a new kind of interaction resulted as the surface $\mathrm{OH}$ groups were converted into surface $\mathrm{O}^{2-}$ ions in contact with the metal. However, evacuation also leads to removal of chemisorbed hydrogen from the surface of the metal and possibly from the metal-support interface. Therefore, it is also possible that the observed long metal-oxygen distance is a consequence of the presence of hydrogen at the metal-support interface. ${ }^{22}$ Furthermore, evacuation also leads to changes in the morphology of the supported clusters, producing more raft-like structures that may be more polarized; thus the relatively short metal-oxygen distances of 2.1-2.2 $\AA$ may be explained by the interaction of metal atoms with small positive charges with oxygen of the interface. ${ }^{22,25}$

The present results are not sufficient to resolve these issues, but they do help to distinguish between two of the possibilities, as follows. As outlined above, the Ir at the interface is inferred to be coordinated principally to four oxygens. The oxygens on the surface of partially hydroxylated $\mathrm{MgO}$ include $\mathrm{O}^{2-}$ as well as oxygen of $\mathrm{OH}^{-}$groups of more than one kind, including protonated $\mathrm{O}^{2-}$ ions terminating the $\mathrm{MgO}$ lattice and $\mathrm{OH}$ groups bonded to $\mathrm{Mg}^{2+}$ ions terminating the lattice. ${ }^{26}$ This results in two limiting cases for the $\mathrm{Ir}$ atoms at the $\mathrm{MgO}$ surface (Figure $12 \mathrm{~A}$ and $\mathrm{B})$.

The two simple models can be described as follows: (1) If the support surface has no hydroxyl groups in contact with the clusters, individual $\mathrm{Ir}$ atoms on the $\mathrm{MgO}(100)$ face are positioned between the oxygens and directly above the $\mathrm{Mg}^{2+}$ ions (Figure 12A). From the $\mathrm{MgO}$ crystallographic distance ${ }^{13}$ and an $\mathrm{Ir}-\mathrm{O}$ coordination distance of $2.6 \AA$ (Table I), an $\mathrm{Ir}-\mathrm{Mg}$ distance of $1.5-1.6 \AA$ is expected. (2) If the $\mathrm{MgO}$ (100) face is fully hydroxylated, ${ }^{26}$ then the $\mathrm{Mg}^{2+}$ ions are covered with $\mathrm{OH}$ groups. Ir atoms on this surface that have an $\mathrm{Ir}-\mathrm{O}$ coordination number of 4 would have

(23) Martens, J. H. A. Ph.D. Thesis. Eindhoven University of Technology, The Netherlands, 1988.

(24) Kampers, F. W. H.; Koningsberger, D. C. Faraday Discuss. Chem. Soc. 1990, 89, 137.

(25) Chang, J.-R.; Gron, L. U.; Honji, A.; Sanchez, K. M.; Gates, B. C. J. Phys. Chem. 1991, 95, 9944.

(26) Lamb, H. H.; Gates, B. C.; Knōzinger, H. Angew. Chem., Int. Ed. Engl. 1988, 27, 1127. 
to be placed between four $\mathrm{OH}$ groups, each positioned on top of a $\mathrm{Mg}^{2+}$ surface ion (Figure 12B). Using the same coordination distances as in the former model and a Mg-OH distance of 2.106 $\AA$ (equal to the $\mathbf{M g}-\mathrm{O}$ distance in $\mathbf{M g O}$ ), an $\mathrm{Ir}-\mathbf{M g}$ distance of 4.1-4.2 $\AA$ is calculated. The Ir-Mg distances indicated by EXAFS (1.6-1.7 $\AA$, Table I) are in agreement with the first but not the second of these limiting-case models.

Although the Ir-Mg distances obtained from EXAFS analysis agree with the interface model depicted in Figure 12A, the low value of the $\mathbf{I r}-\mathbf{M g}$ distance raises questions about the chemical state of the $\mathrm{Ir}$ in the samples. The Ir-Ir coordination distance $(2.72 \AA)$ suggests that the $\mathrm{Ir}$ is in the zerovalent state. In that case, simple addition of the radii of $\mathrm{Mg}^{2+}(0.66 \AA)$ and $\mathrm{Ir}^{0}(1.36$ $\AA$ ) results in an expected $\mathrm{Ir}-\mathrm{Mg}$ distance of approximately $2 \AA$. An Ir-Mg distance of 1.5-1.6 $\AA$ would be expected on the basis of geometrical considerations as argued above, but clearly then not all Ir can be in the zerovalent state. The observed Ir-Mg distance $(1.6-1.7 \AA)$ is somewhat larger than that expected for Ir on undistorted $\mathrm{MgO}$. We suggest that the $\mathrm{Mg}$ ion may move slightly away from the interface Ir atom (Figure 12A), which is as expected if some Ir atoms bear a small positive charge. We thus suggest that at least some of the Ir atoms present in the metal-support interface should be regarded not as $\mathrm{Ir}^{0}$ but instead as $\mathrm{Ir}^{\delta+}$. As mentioned before the Ir clusters were investigated in the presence of hydrogen and were therefore hydrides with possibly a $\mathrm{Ir}^{\delta+}-\mathrm{H}^{\delta-}$ charge distribution. ${ }^{17}$ The removal of these hydride ligands (e.g. by evacuation ${ }^{24}$ or by high-temperature reduction ${ }^{22}$ ) may lead to a direct $\mathrm{Ir}^{\delta+}-\mathrm{O}^{2-}$ interaction with a higher degree of polarization, as suggested for the $\mathrm{I} r$ hydrides. This direct $\mathrm{Ir}^{\delta+}-\mathrm{O}^{2-}$ interaction implies the existence of relatively short (ca. $2.2 \AA$ ) metal-oxygen distances. Such short distances are characteristic of metal subcarbonyls on metal oxides, ${ }^{25}$ and the existence of such short distances in oxide-supported metals has been suggested to be an indication that some of the interface metal atoms bear small positive charges. ${ }^{22,25}$ This short metal-oxygen distance is about the same as the short $\mathrm{Ir}-\mathrm{O}(2)$ distance (about $2.2 \AA$ ) that occurs in $\mathrm{Ir}_{6} / \mathrm{MgO}$ and $\mathrm{Ir}_{n} / \mathrm{MgO}$, and also here it is suggested to be attributable to the $\mathrm{Ir}-\mathrm{O}\left(\mathrm{viz}\right.$. $\mathrm{Ir}^{\delta+}-\mathrm{O}$ ) bonds of the anchoring Ir atom in the octahedral $\mathbf{I r}_{6}$ clusters in direct contact with the support oxygen (Figure 11B).

In summary, on the basis of the observed Ir-Mg distances, we conclude that some Ir in the interface must bear small positive charges. We also conclude that Ir was not present on sites where the surface was fully hydroxylated; it must have been present on sites that were dehydroxylated or partially hydroxylated. The surface ligands are thus inferred to include $\mathrm{O}^{2-}$ and/or $\mathrm{OH}^{-}$ (originating from $\mathrm{H}^{+}$interacting with $\mathrm{O}^{2-}$, as shown in the side view of Figure $12 \mathrm{~A}$ ). The $\mathrm{Ir}-\mathrm{O}$ distance of about $2.6 \AA$ has been similarly observed for a number of conventional supported metals on various metal oxides and zeolites. ${ }^{3-6,8-10,19,27-30}$ This distance was found only with samples characterized by EXAFS spectroscopy in the presence of $\mathbf{H}_{2}$. This metal-oxygen distance thus may be characteristic of interfaces in which hydrogen is present between metal atoms and oxygen ions of metal oxide supports, including zeolites. The observations refer to the following metals: $\mathrm{Rh}^{3-6} \mathrm{Pd},{ }^{27} \mathrm{Re},{ }^{28} \mathrm{Os},{ }^{29} \mathrm{Ir}^{15,24}$ (also this work), and Pt. ${ }^{18,19,30}$ The nature of hydrogen at the interface remains to be elucidated; in one limiting case, it might be protonic and associated primarily with the oxygen, and in another limiting case it might be hydridic and associated primarily with the metal. Removal

(27) Möller, K.; Bein, T. EXAFS and Near Edge Structure; Lagarde, P., Raoux, D., Petiau, J., Eds.; Les Editions de Physique: Les Ulis, France, 1986; Vol. 1, pp C8-231.

(28) Kirlin, P. S.; Van Zon, F. B. M.; Koningsberger, D. C.; Gates, B. C. J. Phys. Chem. 1990, 94, 8439.

(29) Lamb, H. H.; Wolfer, M.; Gates, B. C. J. Chem. Soc., Chem. Commun. $1990,1296$.

(30) Vaarkamp, M.; Van Grondelle, J.; Miller, J. T.; Sajkowski, D. J.; Modica, F. S.; Lane, G. S.; Gates, B. C.; Koningsberger, D. C. Catal. Lett. 1990, 6, 369. of the hydrogen from the interface is accompanied by structural rearrangement of the metal-support interface, ${ }^{22,24}$ which is expected to influence the electronic structure of the metal clusters and thereby the catalytic properties of the supported metals. ${ }^{22}$

\section{Experimental Section}

Catalyst Preparation. A. Ir $/ \mathbf{M g O}$. The sample was prepared by chemisorption of $\left[\mathrm{Ir}_{4}(\mathrm{CO})_{12}\right]$ on $\mathrm{MgO}$, as communicated previously, ${ }^{11}$ followed by decarbonylation. All the steps were carried out in the near absence of air on Schlenk lines and in nitrogen-filled dryboxes; details are given below.

$\left[\mathrm{Ir}_{4}(\mathrm{CO})_{12}\right.$ ] (Strem) was used without further purification. Reagentgrade hexanes were dried by refluxing over sodium benzophenone ketyl. Nitrogen ( $99.999 \%$ ) (Matheson) was purified by passage through traps containing $\mathrm{Cu}_{2} \mathrm{O}$ and activated molecular sieves to remove traces of oxygen and moisture, respectively. The partially dehydroxylated $\mathrm{MgO}$ powder (MCB) was prepared by treatment in flowing oxygen as the temperature was ramped from room temperature to $673 \mathrm{~K}$; this temperature was held for $2 \mathrm{~h}$, and the sample was evacuated and held for a further $14 \mathrm{~h}$ at this temperature. The $\mathrm{MgO}$ was cooled under vacuum to room temperature and removed in the drybox. The surface area of the powder was approximately $75 \mathrm{~m}^{2} / \mathrm{g}$ as determined by $\mathrm{N}_{2}$ adsorption.

The $\mathrm{MgO}$-supported sample was prepared by slurrying [ $\operatorname{Ir}_{4}(\mathrm{CO})_{12}$ ] $(0.029 \mathrm{~g})$ in freshly distilled hexanes $(50 \mathrm{~mL})$ in a Schlenk flask under $\mathrm{N}_{2}$. The $\mathrm{MgO}(2.0 \mathrm{~g})$ was added to the slurry, which was stirred for 4 $\mathrm{h}$ at room temperature. The solid sample was dried by evacuation for $14 \mathrm{~h}$ at room temperature.

The resulting sample was treated in flowing helium while being heated to $573 \mathrm{~K}$ at a rate of $5 \mathrm{~K} / \mathrm{min}$, held at this temperature for $2 \mathrm{~h}$, cooled in flowing helium, and then treated in flowing $\mathrm{H}_{2}$ as it was heated at 5 $\mathrm{K} / \mathrm{min}$ to $573 \mathrm{~K}$. Diffuse reflectance Fourier transform infrared spectroscopy (DRIFTS) was used to characterize the sample at various stages of the preparation; the spectrometer was a Nicolet 7199; the cell and methods are described in a thesis. ${ }^{31}$ The spectra demonstrate that the Ir was fully decarbonylated after the treatment described above. Results presented elsewhere ${ }^{11}$ provide evidence that the intermediate surface structure formed upon adsorption of the $\left[\mathrm{Ir}_{4}(\mathrm{CO})_{12}\right]$ was predominantly $\left[\mathrm{HIr}_{4}(\mathrm{CO})_{11}\right]^{-}$; this was extracted from the surface and identified in solution. ${ }^{11}$

B. Ir 6 / MgO. The sample was prepared by conversion of the intermediate $\left[\mathrm{HI}_{4}(\mathrm{CO})_{11}\right]^{-}$on the $\mathrm{MgO}$ surface to predominantly $\left[\mathrm{I}_{6}(\mathrm{CO})_{15}\right]^{2-}$, which could be extracted from the surface with a solution of [PPN] [Cl] in acetone, as described elsewhere. ${ }^{12}$ The surface reaction giving the hexairidium cluster anion took place as the sample was treated in flowing $\mathrm{CO}$ at atmospheric pressure as the temperature was ramped at $5 \mathrm{~K} / \mathrm{min}$ to $473 \mathrm{~K}$ and held for $8 \mathrm{~h}$. This sample was decarbonylated by treatment in flowing $\mathrm{He}$ at $573 \mathrm{~K}$ for $2 \mathrm{~h}$ followed by treatment in flowing $\mathrm{H}_{2}$ as it was heated at $5 \mathrm{~K} / \mathrm{min}$ to $573 \mathrm{~K}$ and held for $2 \mathrm{~h}$ before cooling to room temperature in flowing $\mathrm{H}_{2}$. The decarbonylation was followed by infrared spectroscopy.

C. $\mathrm{Ir}_{\mathbf{w}} / \mathrm{MgO}$. An Ir/MgO sample that is a typical highly dispersed supported metal catalyst was prepared by impregnation of $\mathrm{MgO}$ with a solution of $\left[\mathrm{Ir}_{4}(\mathrm{CO})_{12}\right]$ in cyclohexane. The $\mathrm{MgO}$ was prepared as follows: $88 \mathrm{~g}$ of $\mathrm{Mg}\left(\mathrm{NO}_{3}\right)_{2} \cdot 6 \mathrm{H}_{2} \mathrm{O}$ was dissolved in $400 \mathrm{~mL}$ of distilled water. This solution was added dropwise with vigorous stirring to a 1000 $\mathrm{mL}$ water/ice mixture in which $200 \mathrm{~mL}$ of concentrated ammonia had been dissolved. After all the $\mathrm{Mg}\left(\mathrm{NO}_{3}\right)_{2}$ solution had been added and the ice melted, the precipitate was filtered, suspended in $500 \mathrm{~mL}$ of a water/ ice mixture, and filtered again. This procedure was repeated until the $\mathrm{pH}$ of the suspension was 7. After the last filtration, the precipitate was dried overnight at $393 \mathrm{~K}$ and ground to a white powder, which was calcined in nitrogen at $473 \mathrm{~K}$ for $2 \mathrm{~h}$ (heating rate, $5 \mathrm{~K} / \mathrm{min}$ ) to remove nitrogencontaining residues. The resulting $\mathrm{MgO}$ powder had a surface area of $119 \mathrm{~m}^{2} / \mathrm{g}$ (determined by $\mathrm{N}_{2}$ adsorption). The $\mathrm{MgO}$ was partially dehydroxylated by calcining in vacuum at $873 \mathrm{~K}$ for $8 \mathrm{~h}$ (heating rate, $5 \mathrm{~K} / \mathrm{min}$ ). [ $\left.\operatorname{Ir}_{4}(\mathrm{CO})_{12}\right]$ (Alfa, used without further purification) and cyclohexane (dried over sodium benzophenone ketyl and used immediately after being distilled) were mixed and stirred with $\mathrm{MgO}$ under nitrogen for $4 \mathrm{~h}$. The solid was filtered and dried overnight under vacuum at room temperature. The Ir loading was $0.8 \mathrm{wt} \%$. The solid was decomposed by heating in $\mathrm{N}_{2}$ at $473 \mathrm{~K}$ for $2 \mathrm{~h}$, reduced in flowing $\mathrm{H}_{2}$ at $623 \mathrm{~K}$ for $8 \mathrm{~h}$ (heating rate $5 \mathrm{~K} / \mathrm{min}$ ), and passivated in air at room temperature prior to storage.

(31) Maloney, S. D. Ph.D. Thesis. University of Delaware, 1989. 
EXAFS Measurements. EXAFS measurements of the supported iridium catalysts were performed at EXAFS station 9.2 of the Wiggler beamline of the synchrotron radiation source (SRS) at Daresbury, U.K. The station was operated with a double crystal monochromator, $\mathrm{Si}(220)$, detuned to $50 \%$ intensity to minimize the presence of higher harmonics in the beam. The estimated resolution was $3 \mathrm{eV}$ at the $P t \mathrm{~L}_{\text {III }}$ edge $(11564 \mathrm{eV})$. The measurements were carried out in the transmission mode with optimized ion chambers to measure the radiation intensity. Data were collected at each energy for $1 \mathrm{~s}$, and results from several scans ( $\mathrm{Ir}_{4} / \mathrm{MgO}, 4$ scans; $\mathrm{Ir}_{6} / \mathrm{MgO}, 2$ scans; $\mathrm{Ir}_{n} / \mathrm{MgO}, 6$ scans) were averaged to minimize high- and low-frequency noise.

The supported Ir samples were pressed into thin self-supporting wafers (each with an absorbance of approximately 2.5 ) and mounted in an insitu EXAFS cell. ${ }^{32}$ The $\mathrm{Ir}_{4} / \mathrm{MgO}$ sample had been prepared at the University of Delaware and sealed inside three layers of glass vials, each individually sealed with parafilm, the vial cap, and electrical tape. The sample was transported to Daresbury and loaded into the EXAFS cell at the synchrotron under $\mathbf{N}_{2}$ in a drybox. Data were collected with the sample in the presence of $\mathrm{H}_{2}$ at approximately liquid nitrogen temperature. A fraction of the precursor ( $\left[\mathrm{HI}_{4}(\mathrm{CO})_{11}\right]^{-}$supported on $\mathrm{MgO}$ ), handled in the same way as the samples characterized with EXAFS spectroscopy, was resealed and returned to Delaware, where it was characterized by infrared spectroscopy and found to be essentially unchanged. These results confirm the lack of contamination of the samples.

The sample consisting predominantly of $\left[\operatorname{Ir}_{6}(\mathrm{CO})_{15}\right]^{2-}$ on $\mathrm{MgO}$ was prepared from the sample consisting predominantly of $\left[\mathrm{HIr}_{4}(\mathrm{CO})_{11}\right]^{-}$on $\mathrm{MgO}$ and then decarbonylated, as described above, with the work done in Delaware. The sample transport and handling and the EXAFS measurements were carried out as described above for the sample prepared by decarbonylation of the $\mathrm{MgO}$-supported $\left[\mathrm{HIr}_{4}(\mathrm{CO})_{11}\right]^{-}$.

The $\mathrm{Ir}_{n} / \mathrm{MgO}$ sample was rereduced as it was heated in flowing $\mathrm{H}_{2}$ to $623 \mathrm{~K}$ and held for $1 \mathrm{~h}$. EXAFS measurements were made with the sample in a $\mathrm{H}_{2}$ atmosphere; details are as given above for the other samples.

EXAFS data were also collected to characterize the reference materials: The $\mathrm{Pt} \mathrm{L}_{\mathrm{III}}$ edge (11 $564 \mathrm{eV}$ ) of $\mathrm{Pt}$ foil and $\mathrm{Na}_{2} \mathrm{Pt}(\mathrm{OH})_{6}$ and the Ir $L_{\text {III }}$ edge of IrAl alloy were measured at liquid nitrogen temperature. ${ }^{21}$ Ir powder was measured as received at room temperature to calibrate the d-band density of states obtained from the $\mathrm{L}_{\text {III }}$ white line.

EXAFS Data Analysis. A. Data Reduction. Standard procedures were used to extract the EXAFS data from the measured absorption spectra. Normalization was done by dividing the absorption intensities by the height of the absorption edge $e^{3}$ and subtracting the background by using cubic spline routines. ${ }^{3}$ The final EXAFS function was obtained by averaging the individual background-subtracted and normalized EXAFS data. The noise amplitude determined from the EXAFS average routine was $10^{-3}, 2 \times 10^{-3}$, and $1.5 \times 10^{-3}$ (determined at $k=17 \AA^{-1}$ ); the signal amplitude around $k=4 \AA^{-1}$ was $8 \times 10^{-2}, 8.4 \times 10^{-2}$, and 5.5 $\times 10^{-2}$, leading to a signal to noise ratio of 80,40 , and 36 for $\mathrm{Ir}_{4} / \mathrm{MgO}$, $\mathrm{Ir}_{6} / \mathrm{MgO}$, and $\mathrm{Ir}_{n} / \mathrm{MgO}$, respectively. The standard deviations were calculated for the individual EXAFS data points as a measure of the experimental errors in the final EXAFS function.

The EXAFS data analysis is usually performed on an isolated part of the data obtained by an inverse Fourier transformation over a selected range in $r$ space. $^{3}$ The average isolated EXAFS function was used in the analysis in this work. The standard deviation calculated from the individual data points of the several isolated EXAFS functions provided a measure of the experimental error in the average isolated EXAFS function.

B. Reference Data. Pt foil was used as a reference for the Ir-Ir interactions, $\mathrm{Na}_{2} \mathrm{Pt}(\mathrm{OH})_{6}$ for the $\mathrm{Ir}-\mathrm{O}$ interactions, and IrAl alloy for the $\mathbf{I r}-\mathbf{M g}$ interactions. The justification for the use of these references is provided by both theoretical ${ }^{33,34}$ and experimental ${ }^{29,34}$ results.

The data analysis procedures used to obtain the reference data for $\mathrm{Pt}$ foil and $\mathrm{Na}_{2} \mathrm{Pt}(\mathrm{OH})_{6}$ are described elsewhere. ${ }^{21}$ The determination of the EXAFS reference data for $\mathrm{Pt}$ foil and $\mathrm{Na}_{2} \mathrm{Pt}(\mathrm{OH})_{6}$ was straightforward, as the first-shell peak in $r$ space ( $\mathrm{Pt}-\mathrm{Pt}$ or $\mathrm{Pt}-\mathrm{O}$ ) shows no overlap with higher shells. However, determination of the EXAFS reference data for the IrAl alloy data was more difficult, as the peak of interest ( $8 \mathrm{Al}$ neighbors of Ir at $2.58 \AA$ ) shows an overlap in the Fourier transform with the Ir-Ir contribution ( 6 Ir neighbors at $2.98 \AA$ ). Thus, the Ir-Ir contribution had to be subtracted from the data prior to the determination of the $\mathrm{Ir}-\mathrm{Al}$ reference. The calculation was performed as

(32) Kampers, F. W. H.; Maas, T. M. J.; Van Grondelle, J.; Brinkgreve, P.; Koningsberger, D. C. Rev. Sci. Instrum. 1989, 60, 2635.

(33) Teo, B. K.; Lee, P. A. J. Am. Chem. Soc. 1979, 101, 2815.

(34) Lengeler, B. J. Phys. (Paris) C8 1986, 47, 75. follows: An Ir-Ir contribution was calculated with the coordination number $N=6$ and the distance $R=2.98 \AA$ (these are crystallographic parameters), and the Debye-Waller factor $\left(\Delta \sigma^{2}\right)$ and inner potential correction $\left(\Delta E_{0}\right)$ were adjusted until the Ir-Ir peak in a $k^{3}$-weighted Fourier transform of the EXAFS difference file between the experimental results and the calculated $\mathrm{Ir}-\mathrm{Ir}$ contribution was reduced to zero (final values: $\left.\Delta \sigma^{2}=-0.001 \AA^{2}, \Delta E_{0}=-3.3 \mathrm{eV}\right)$. The resulting difference file was then Fourier transformed (with $k^{3}$ weighting, $2.7<k<12.0 \AA^{-1}$ ), and the unperturbed $\mathrm{Ir}-\mathrm{Al}$ peak was isolated with an inverse transform by using a window with $0.98<r<2.98 \AA$. To obtain a reference that is reliable over a larger range of $k$, a theoretical Ir-Al EXAFS function was calculated with the FEFF program developed by Lu and Rehr. ${ }^{35}$ The theoretical reference was adjusted to agree with the (limited) Ir-Al reference data obtained as described above for use in the analysis of the Ir-Mg contribution. The theory then allowed the use of a larger interval in $k$ space for the fitting of the Ir data; therefore the theoretical Ir-Al reference was used in the EXAFS data analysis.

C. Fits in $k$ Space and in $r$ Space: Use of Both $k^{1}$ - and $k^{3}$-Weighted Fourier Transforms. The EXAFS data analysis was performed with the experimentally determined phase shifts and backscattering amplitudes for the Ir-Ir and Ir-O contributions, and the theoretical reference for the Ir-Al contribution. A nonlinear least squares multiple-shell fitting routine was used to fit the data in $k$ space (with $k^{n}$ weighting). The program allowed simultaneous monitoring of the unweighted and the $k^{n}$-weighted fits in $k$ space as well as the sum of the squares of the residuals between the fit and the data for the $k^{n}$-weighted function and the sum of the squares of the residuals between the fits and the data for both the magnitude and the imaginary parts of the Fourier transforms.

The difference file technique was applied together with phase-corrected Fourier transforms to identify the different contributions in the EXAFS data. ${ }^{3}$ To determine reliably the parameters characterizing the high- $Z$ (Ir) and low- $Z$ (O and $\mathrm{Mg}$ ) contributions, multiple-shell fitting in $k$ space (simultaneously monitoring the fit in $r$ space) was done with application of both $k^{1}$ and $k^{3}$ weighting; use of both is a prerequisite as the dependence on $k$ of the backscattering amplitude of low- $Z$ elements (such as $\mathrm{O}$ and $\mathrm{Mg}$ ) is different from that of high- $Z$ elements (such as Ir); the backscattering amplitude of a low- $Z$ element becomes very small at $k \geq 7 \AA^{-1}$, whereas that of a high- $Z$ scatterer is still significant at higher values of $k .^{14}$ Application of only $k^{3}$ weighting leads to an underestimation of the contributions of low- $Z$ scatterers, and application of only $k^{1}$ weighting leads to an underestimation of the contributions of high- $Z$ scatterers.

Optimization of both the $k^{1}$ - and $k^{3}$-weighted fits in both $k$ space and $r$ space results in a better decoupling of the EXAFS parameters $\left(N, \Delta \sigma^{2}\right.$, $R$, and $\Delta E_{0}$ ) than could be realized if only more restricted criteria (using only $k^{1}$ or $k^{3}$ ) were applied in the fitting; this fitting procedure therefore gives a more reliable set of parameters than could be estimated with the more restricted criteria. ${ }^{36}$

In some cases the EXAFS coordination numbers $N_{\mathrm{E}}$ obtained in the data analysis had to be corrected for the difference in distance between the absorber-backscatterer pair of the reference shell and that of the shell to be analyzed. This correction is required because the factor $\exp (-2 R / \lambda)$ in the EXAFS formula is not negligible. ${ }^{14}$ The correct coordination number $N$ is therefore $N_{\mathrm{E}} / \exp \left\{-2\left(R-R_{\text {ref }}\right) / \lambda\right\} ; \lambda$ was taken to be equal to $6 \AA$, which is a reasonable approximation for values of $k$ $>3 \AA^{-1}$. $^{37}$

D. Analysis of the EXAFS Data for the MgO-Supported Ir Samples. Analysis of the EXAFS data for each sample was performed in an isolated part of the spectrum. The data were Fourier transformed ( $k^{3}$ weighting) followed by an inverse Fourier transformation with a window $\Delta r\left(\mathrm{Ir}_{4}\right)$ $\mathrm{MgO}, 2.6<k<15.0 \AA^{-1}, 0.7<r<4.0 \AA ; \mathrm{Ir}_{6} / \mathrm{MgO}, 2.6<k<13.6$ $\AA^{-1}, 0.5<r<3.3 \AA$; and $\mathrm{Ir}_{n} / \mathrm{MgO}, 2.6<\mathrm{k}<16.2 \AA^{-1}, 0.8<r<4.8$ $\AA$ ). These isolated EXAFS functions are now referred to as the "primary EXAFS"

The $\operatorname{Ir}-\operatorname{Ir}(1)$ contribution was estimated first, as it is the largest component in the EXAFS spectrum; it was estimated in $k$ space by applying a fit determined with $k^{3}$ weighting of the data with $k \geq 6 \AA^{-1.17}$ The contribution of the low- $Z$ scatterers present in the data is largely suppressed by this procedure. An Ir-Ir EXAFS function was then calculated with the first-guess parameters obtained from the provisional fit. This IrIr (1) contribution was subtracted from the primary EXAFS, and the resulting difference file was analyzed further for $\mathrm{I} r-\mathrm{O}$ contributions by

(35) Lu, D.; Rehr, J. J. J. Phys. (Paris) C8 1986, 47, 67.

(36) Kampers, F. W. H. Ph.D. Thesis. University of Eindhoven, The Netherlands, 1988.

(37) Stern, E. A.; Bunker, B. A.; Heald, S. M. Phys. Rev. B 1980, 21, 5521. 
determining the $\mathrm{Ir}-\mathrm{O}(1)$ contribution that agreed best with the difference file in a $k^{i}$-weighted $\mathrm{Ir}-\mathrm{O}$ phase-corrected Fourier transform.

The estimates of the $\operatorname{Ir}-\operatorname{Ir}(1)$ and $\mathrm{Ir}-\mathrm{O}(1)$ contributions were further optimized by performing multiple-shell fits in $k$ space and in $r$ space with both $k^{1}$ and $k^{3}$ weighting. Small but significant deviations still remained in the range $1.5<r<2.2 \AA$. Further analysis showed that this deviation was associated with the contribution of another low- $Z$ scatterer. The plausible candidates for the third scatterer are carbon contaminants ${ }^{15}$ or $\mathrm{Mg}$ cations of the MgO support. With the aid of phase-corrected Fourier transforms, it was established that an $\mathrm{Ir}-\mathbf{M g}$ contribution was present. Finally, for $\mathrm{Ir}_{6} / \mathrm{MgO}$ and $\mathrm{Ir}_{n} / \mathrm{MgO}$ it was necessary to include an Ir$O(2)$ contribution in the same way. Likewise, $\operatorname{Ir}-\operatorname{Ir}(2)$ contributions were added for $\mathrm{Ir}_{4} / \mathrm{MgO}$ and $\mathrm{Ir}_{n} / \mathrm{MgO}$, and also $\operatorname{Ir}-\operatorname{Ir}(3)$ for $\mathrm{Ir}_{n} / \mathrm{MgO}$. The final coordination parameters were then obtained as described above by determining multiple-shell fits in $k$ space and in $r$ space with $k^{1}$ and $k^{3}$ weighting.

The resulting coordination parameters are given in Table $I$. The standard deviations given for the $\mathrm{Ir}_{4} / \mathrm{MgO}$ and the $\mathrm{Ir}_{6} / \mathrm{MgO}$ samples are calculated from the covariance matrix including the actual noise obtained for the Fourier filtered EXAFS function as outlined above. The value of the goodness of fit $\left(\epsilon_{y}{ }^{2}\right)$ as defined in the Report on Standards and Criteria in XAFS Spectroscopy ${ }^{38}$ for $\mathrm{Ir}_{4} / \mathrm{MgO}$ was $\epsilon_{\nu}{ }^{2}=1.3$ with 16 fit parameters and 3.8 degrees of freedom. The weakest contribution to this fit was the Ir-Mg coordination. The confidence limit of this contribution was calculated by first determining the $\epsilon_{r-4}{ }^{2}$ value for the goodness of fit incorporating only three shells: $\operatorname{Ir}-\operatorname{Ir}(1), \operatorname{Ir}-\mathrm{O}(1)$, and $\operatorname{Ir}-\operatorname{Ir}(2) . \epsilon_{\mathrm{r}-\mathrm{S}^{2}}=$ 5.3 was obtained, with 12 fit parameters and 7.8 degrees of freedom. Using these values for $\epsilon^{2}$, the F-test was applied, ${ }^{39}$ and it showed, at an $85 \%$ confidence level, that the $\mathrm{Ir}-\mathrm{Mg}$ contribution is present. Thus, we feel confident that the data for $\mathrm{Ir}_{4} / \mathrm{MgO}$ are best represented by a fourshell fit. For $\operatorname{Ir}_{6} / \mathrm{MgO}, \epsilon_{\nu}{ }^{2}=2.1$ (with 16 fit parameters and 1 degree of freedom) was obtained. Our analysis package is not yet able to perform a statistical analysis with 24 fit parameters as is necessary for the analysis of the $\mathrm{Ir}_{n} / \mathrm{MgO}$ sample. No errors are given for this sample in Table $\mathrm{I}$. The estimated errors for the coordination numbers vary from $10 \%$ for the dominant $\operatorname{Ir}-\operatorname{Ir}(1)$ shell to $30 \%$ for the higher shells. The standard deviation of the coordination distances ranges from 0.01 for the $\operatorname{Ir}-\operatorname{Ir}(1)$ shell to 0.03 for the higher shells.

\section{Conclusions}

Ir/MgO catalysts with various nuclearities have been characterized with EXAFS spectroscopy to elucidate the structure of the metal-support interface. Beginning with the precursor $\left[\mathrm{Ir}_{4}(\mathrm{CO})_{12}\right]$ supported on $\mathrm{MgO}, \mathrm{Ir}_{4} / \mathrm{MgO}$ was prepared via the

(38) Lytle, F. W.; Sayers, D. E.; Stern, E. A. Physica B (Amsterdam) $1989,158,701$

(39) Bevington, P. R. Data Reduction and Error Analysis for the Physical Sciences; McGraw-Hill: New York, 1969. intermediate $\left[\mathrm{HI}_{4}(\mathrm{CO})_{11}\right]^{-}$, and separately, $\mathrm{Ir}_{6} / \mathrm{MgO}$ was prepared via $\left[\operatorname{Ir}_{6}(\mathrm{CO})_{15}\right]^{2-}$. With EXAFS spectroscopy, it has been shown that upon careful decarbonylation, the cluster nuclearity of the intermediate is maintained in the final product. More severe treatment in $\mathrm{H}_{2}$ of $\left[\mathrm{Ir}_{4}(\mathrm{CO})_{12}\right]$ on $\mathrm{MgO}$ results in an $\mathrm{Ir}_{n} / \mathrm{MgO}$ catalyst with larger, structurally nonuniform Ir clusters.

EXAFS analysis of the first and higher Ir-Ir shells and model calculations show that the $\mathrm{Ir}_{4} / \mathrm{MgO}$ sample can be modeled as a mixture of $\mathrm{Ir}_{4}$ tetrahedra and square rafts. The EXAFS data characterizing $\mathrm{Ir}_{6} / \mathrm{MgO}$ are well represented by a mixture of $\mathrm{Ir}_{6}$ octahedra and (100) rafts, and the data characterizing $\mathrm{Ir}_{n} / \mathrm{MgO}$ lead to a model consisting of Ir metal clusters, approximately hemispherical and averaging $10 \AA$ in diameter, with a (100) basal plane in contact with the $\mathrm{MgO}$ support.

Ir-O contributions with a coordination distance of $2.6 \AA$ and associated with the metal-support interaction are large in all three samples. The Ir atoms at the interface are approximately fourfold coordinated to oxygen, and it is suggested that the Ir clusters are predominantly present on the (100) faces of $\mathrm{MgO}$, where a fourfold coordination is most easily pictured. The EXAFS data indicate an $\mathbf{I r}-\mathbf{M g}$ contribution at $1.7 \AA$, which implies that Ir atoms at the interface are positioned at surface $\mathbf{M g}$ ions on (partially) dehydroxylated parts of the $\mathrm{MgO}$ faces. Relatively long (2.5-2.7 A) metal-oxygen distances are found in supported metals only when they are characterized in a $\mathrm{H}_{2}$ atmosphere, and thus it is postulated that this distance characterizes the interaction between reduced metal atoms and surface oxygen atoms or the interaction between these interfacial metal atoms and oxygen atoms with hydrogen present in the metal-support interface.

Small $\mathrm{Ir}-\mathrm{O}$ contributions with a coordination distance of $\mathbf{2 . 2}$ $\AA$, found to be characteristic of $\mathrm{Ir}_{6} / \mathrm{MgO}$ and $\mathrm{Ir}_{n} / \mathrm{MgO}$ samples, but not $\mathrm{Ir}_{4} / \mathrm{MgO}$, are not ascribed to an oxidic fraction of the Ir but instead are thought to be an indication of the metal-support interface where positively charged metal atoms interact with oxygen at the interface. Some of these Ir atoms at the interface may penetrate into $\mathrm{Mg}$ vacancies.

Acknowledgment. We thank Prof. R. A. Van Santen for helpful discussions. This research was supported by the Netherlands Organization for Scientific Research (NWO) and the U.S. Department of Energy, Office of Energy Research, Office of Basic Energy Sciences (Grant FG0287ER 13790). The international collaboration was supported by a NATO travel grant. 